\title{
Developing a scientific journal in a changing world
}

\author{
Bernard Pochet ${ }^{(1)}$, Gilbert Berben ${ }^{(2)}$, Cédric Vermeulen ${ }^{(3)}$ \\ (1) University of Liège - Gembloux Agro-Bio Tech. CARE Uliège Library. Passage des Déportés, 2. BE-5030 Gembloux \\ (Belgium). E-mail: Bernard.pochet@uliege.be \\ (2) Walloon agricultural Research Center. Department Valorization of agricultural Products. Henseval Building. Chaussée de \\ Namur, 24. BE-5030 Gembloux (Belgium). \\ (3) University of Liège - Gembloux Agro-Bio Tech. Biosystems Engineering (Biose). Tropical and subtropical Regions \\ Forestry Laboratory. Passage des Déportés, 2. BE-5030 Gembloux (Belgium).
}

This article is distributed under the terms and conditions of the CC-BY License (http://creativecommons.org/licenses/by/4.0)

After a brief historical overview, this article presents the current situation of the journal BASE, its objectives, its challenges, its functioning and its limitations. BASE is a journal that publishes articles in open access in the field of agricultural sciences in the broad sense and offers a free service to authors. The editorial board pays particular attention to the transparency of its validation and editing processes. The data presented allow BASE to be compared with other international scientific journals. At the end of the article, after outlining some of the difficulties encountered, several prospects are described that should address the disadvantages arising from the multidisciplinary nature of BASE.

Keywords. Academic journal, open access, impact factor, scholarly publishing, peer reviewing.

\section{Faire évoluer une revue scientifique dans un monde changeant}

Après un bref rappel historique, cet article présente la situation actuelle de la revue BASE, ses objectifs, ses enjeux, son fonctionnement et ses limites. BASE est une revue qui publie en Open Access des articles du domaine des sciences agronomiques au sens large et offre un service gratuit aux auteurs. Le comité de rédaction est particulièrement attentif à la transparence de ses processus de validation et d'édition. Les chiffres présentés permettent de situer BASE dans l'ensemble des revues scientifiques internationales. En fin d'article, après la description de quelques difficultés, plusieurs perspectives sont décrites. Elles devraient rencontrer les inconvénients du caractère multidisciplinaire de BASE.

Mots-clés. Revue académique, libre accès, facteur d'impact, publication scientifique, revue par les pairs.

\section{INTRODUCTION}

When BASE was created in 1997, the journal and its ambitions were presented in a short text published in the very first issue (Baudoin, 1997). In 2002, an editorial outlined the situation after five years of publication (Pochet, 2002). In 2009, another editorial announced the indexation of BASE in the Science Citation Index (Pochet \& Baudoin, 2009). This status enabled BASE to obtain an impact factor and increased its visibility significantly. Even now, this remains a source of attraction for authors. Moreover, the number of articles submitted annually increased from 80 in 2007 to 279 five years later. This number has remained constant since 2012.

The purpose of this article is to review the situation of BASE after two decades of publication, a period during which scientific communication has evolved significantly. The questioning by part of the scientific community of the impact factor as the only means of evaluating the quality of publications (Satyanarayana, 2010; Casadevall \& Fang, 2014; Callaway, 2016) has led to the creation of alternative metrics (Galligan \& Dyas-Correia, 2013); in addition, the emphasis on the weaknesses of the conventional peer review process (Margalida \& Colomer, 2016; Murphy, 2016) and the numerous experiments that have been made with open review systems (Bon, 2015) have appealed to scientists. Above all, however, there have been major advances in open access, the system adopted by journals such as BASE, which consists of offering a free service to authors and completely free access to published articles. These journals are revolutionizing a system hitherto dominated by paid publishers that had acquired a quasi-monopoly position.

This movement has unfortunately been accompanied by a series of problems such as the advent of predatory publishers (Butler, 2013) and APCs (article processing charges) that can amount to several thousand euros in order to publish in open access 
(Crawford, 2017; Wenzler, 2017). The appearance of an increasing number of false impact factors (see https://predatoryjournals.com/metrics/) has made the situation even more complex. As a result, journals must be more transparent than ever and demonstrate the quality of their article validation and editing processes as well as the ethical nature of their approaches. BASE fully reflects these new commitments.

\section{OBJECTIVES}

In 1997, BASE succeeded an earlier journal entitled Bulletin des Recherches Agronomiques de Gembloux. From the start, the intention was to be a showcase for the research results of the 'Centre de Recherches agronomiques de Gembloux', which later became the 'Centre wallon de Recherches agronomiques', and of the 'Faculté des Sciences agronomiques de Gembloux', which became the 'Gembloux Agro-Bio Tech', the 11 ${ }^{\text {th }}$ faculty of the University of Liège.

This showcase role has given BASE a broad multidisciplinary scope, covering original articles in the fields of agronomic sciences, forestry, nature and landscape, environmental sciences and technologies, chemistry and bio-industries.

BASE is therefore mainly a service offered to researchers from the Gembloux scientific community. It is also their most frequently selected journal for publication. Articles published in BASE stem from young researchers and doctoral students as well as from established authors.

However, BASE is also a very open journal. Over the last 15 years, although almost $60 \%$ of the articles published have originated from Belgium, 26\% have come from Africa and $8 \%$ from the rest of Europe.

Whatever the fate of the articles submitted, the editorial board is committed to providing explicit feedback to the authors, enabling them to improve their research and writing work.

\section{QUALITY AND TRANSPARENCY}

With the above-mentioned developments in the world of scientific publishing, it seems crucial to demonstrate the quality of all the steps that will turn a submitted manuscript into a published article in BASE.

With the journal's inclusion in the Directory of Open Access Journals (DOAJ) in 2004, then in the Science Citation Index in 2008 and finally in Scopus in 2009, the publication process has become highly professionalized, notably through the hiring of a publisher.

Authors can now complete the metadata of their own manuscript thanks to the implementation of Open
Journal Systems (OJS) in 2014. Upon submission, all co-authors are automatically notified. During the whole process, which besides an initial check (relevance to the journal, compliance with the authors' guide, ethical aspects, plagiarism and language quality), may include being considered by the editorial board several times and a double-blind peer review, the progress of a manuscript can be followed by a corresponding author at any time.

As well as detailed instructions to authors, the BASE websites (at http://www.pressesagro.be and https://popups.uliege.be) list all the members of the editorial board with their affiliations and highlight all points for attention and the deadlines for each stage. A computer graphic (see 'ABOUT' menu) gives BASE users an overview of the publication process.

Suggestions and requests from the Open Access Scholarly Publishers Association (OASPA) and the Committee on Publication Ethics (COPE), have led to significant improvements in the processes, especially with respect to communication and to article checking and editing. After meeting all their quality criteria, the journal BASE became a member of these two organizations in January 2018.

\section{BASE AND OPEN ACCESS}

Since 2004, open access has also been a focus for BASE. Publishing in open access involves more than just giving free access to articles. It means making public research data accessible and giving readers the freedom to copy, distribute and communicate articles and to adapt, remix, transform and create content from these articles.

The DOAJ and OASPA prefer the CC BY licence (CC for Creative Commons, and BY for the obligation to mention the source). This licence has been adopted for articles published in BASE since 2015. Limitations introduced by other more closed licences (for example, no commercial use or no modification) unnecessarily prevent the use of items in many situations. Using an open licence, such as the CC BY licence, allows knowledge to be disseminated more widely, especially as most of the research published in BASE is publicly funded.

BASE's business model, based on institutional and public funding, makes it possible to offer readers and authors a free service. This aspect is particularly important, as open access is too often associated with the negative image of very high charges for authors (the APC). In fact, data recorded in the DOAJ show that only $30 \%$ of journals charge authors. BASE, by offering a totally free service, wants to distinguish itself from this practice, which tarnishes the image of open access. 


\section{BASE AND ITS PROCESSES}

Of the 331 international journals in the field of 'Agronomy and Crop Science' recorded by Scimago Journal \& Country Rank (https://www.scimagojr. $\mathrm{com} /$ ), BASE is the only journal in open access, with an impact factor, that publishes articles in English and in French. This distinctive characteristic regularly attracts articles of lesser quality (due to quality of language, outdated bibliography, poor experimental design, a subject of mainly local interest, lack of originality, etc.) and leads to a particularly high average rejection rate. Over the last five years, this has reached 83\%. In 2017, the average duration of the rejection decision was 41 days. Of the 223 rejections recorded, 33 were notified to the authors within a week and 138 within a month. Fortunately, the step-by-step process and the monthly meetings of the editorial board allow the rapid rejection of manuscripts with obvious deficiencies, together with prompt communication of this decision to the authors. The process is obviously longer for accepted manuscripts. The average duration for the acceptance of the final version of a manuscript is 8 months.

As BASE covers many scientific disciplines, the list of reviewers is particularly long (more than 1,000 people for the last 10 years). For the validation of articles, at least two reviewers are requested. Identifying and obtaining the agreement of two peers is a lengthy task. Competent scientists are generally overworked and overstretched. Reviewer work is also poorly recognized and rarely valued within the mechanisms for promoting researchers and teachers in universities.
It is usually necessary to contact about 10 researchers before obtaining a proofreading agreement. The corresponding author must provide a list of potential readers when they submit a manuscript. However, after analysis, it often turns out that these people are or have been in contact with the authors, have been co-authors, members of an author's thesis committee or even colleagues.

BASE allocates a time limit of one month to the reviewer. However, this deadline is rarely adhered to and, apart from sending reminders, the editorial board has no means of shortening it.

Over the last five years, BASE has validated and published 507 articles, including 81 in five special issues. Approximately half of these articles were in French and the other half in English. The proportion of articles in English has slightly increased over time (Figure 1).

\section{BASE IN A FEW FIGURES}

For the year 2017 alone, OJS data counted 463,816 downloads of articles in BASE. For the same year, PoPuPS statistics, the second web site for BASE, indicate 491,592 article views (in html). The total number of downloads is therefore close to one million, without considering access via platforms such as EBSCO or Proquest, which also offer full access to BASE articles. In addition, it is possible to access a number of articles which have been included by authors in institutional repositories such as ORBi, the

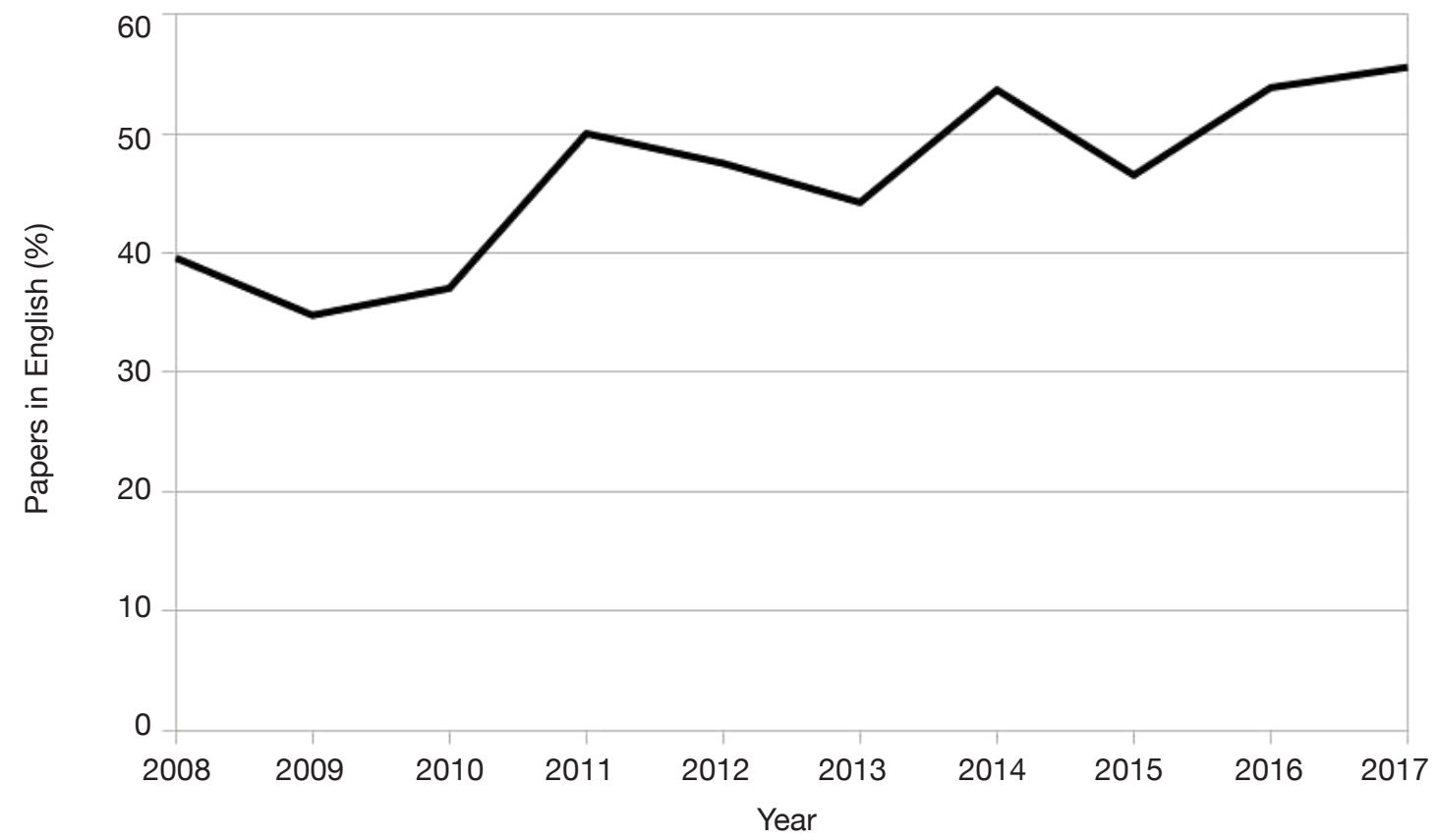

Figure 1. Proportion of articles in English over the last 10 years - Proportion d'articles en anglais sur les 10 dernières années. 
repository of the University of Liège. Providing open access policy is therefore a policy that works and it ensures a wide audience for researchers who choose BASE.

BASE as a journal is included in the main general bibliographic databases and specialized bibliographic databases. This indexation is also an important source of visibility.

The bibliographical database Scopus counts 4,743 citations out of the 21 volumes of BASE that have been published. The number of citations has increased from year to year (Figure 2). The latest impact factor (Clarivate Analytics) published is the IF 2017. It is 0.79 , compared with 0.43 the previous year. This increase is explained by the number of citations (63) in the special issue 'AgricultureIsLife'. The Scopus and Google Scholar data confirm this growth in citation indices. For example, BASE's CiteScore 2017 has increased from 0.62 to 0.93 . Although these indices do not constitute a goal in themselves, they reflect the perception of BASE in the scientific world. Paradoxically, this impact factor is considered very modest for some areas, while for other scientific sectors it is competitive with the reference journals. This is one of the ambiguities of BASE.

\section{PROSPECTS}

This rather positive description should not prevent us from stressing some of the difficulties encountered, mainly because of the multidisciplinary nature of BASE. In addition to the large number of reviewers and the difficulty in completing the peer review quickly, the admission of certain manuscripts is regularly the subject of debate. It is also financially impossible to hire a specialized publisher for each field. The members of the editorial board play this role. Although it is becoming more common for mega-journals to cover a wide range of scientific fields, the multidisciplinarity of BASE can prove to be a disadvantage because, unlike mega-journals, BASE publishes only a limited number of articles per year. As a result, over a limited period of time, not all possible fields are represented. Because of this, authors, both from our own institutions and elsewhere, often prefer to submit their manuscripts to more specialized journals that better reflect their field of competence. This choice is also guided by career opportunities, linked to the importance that the impact factor and the $\mathrm{H}$ index still have in scientists' evaluation processes.

However, it would be out of the question for BASE to lose its multidisciplinary nature, which represents its very essence. Attention must therefore be paid to the quality of the editorial board. In order to maintain its dynamism and representativeness, the list of members is periodically reviewed by internal call inside the 'Centre wallon de Recherches agronomiques' and 'Gembloux Agro-Bio Tech'. All areas covered must be mastered by at least one member.

In order to maintain the interest of BASE readers, the editorial board intends to publish thematic issues such as the recently published special issues 'AgricultureIsLife' and ' $2^{e}$ Atelier Nitrate-Eau'. This obviously depends on receiving enough quality manuscripts on a specific theme. Another approach would be to offer young researchers the opportunity to submit well-structured short notes on innovative topics.

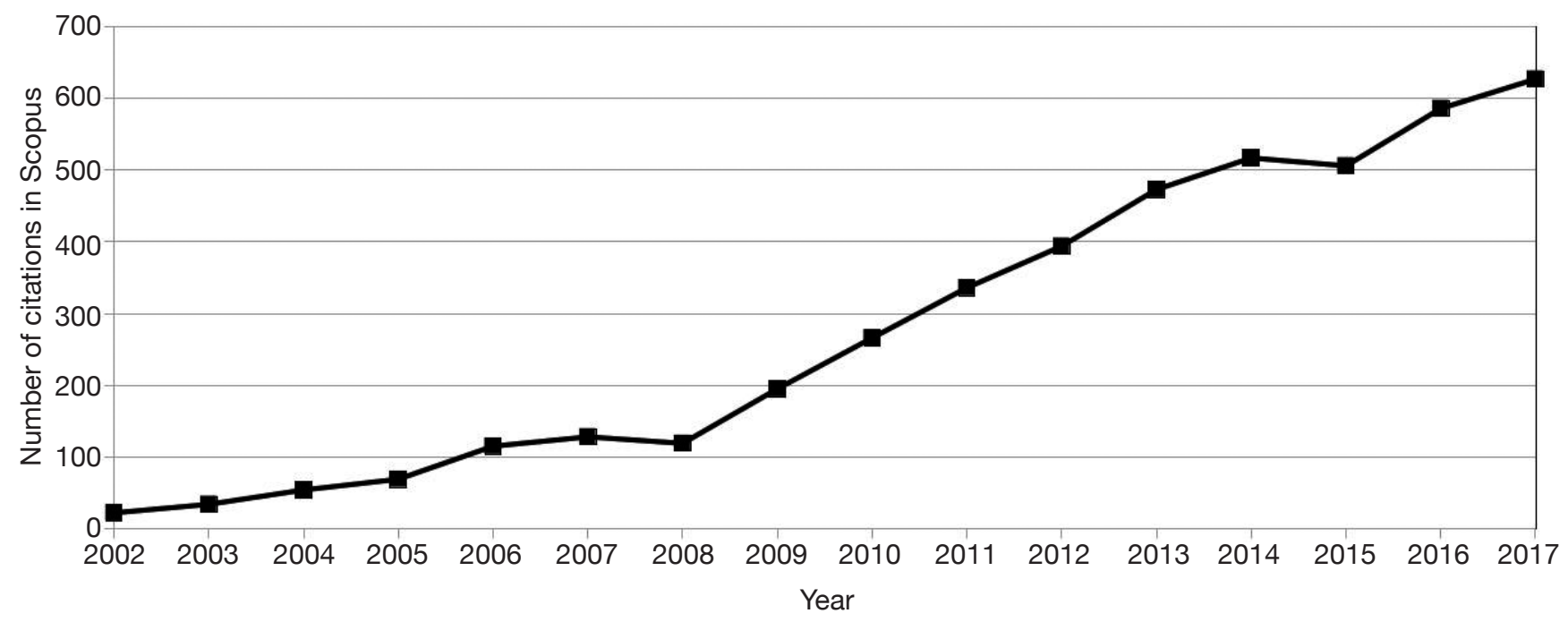

Figure 2. Evolution of the number of citations in Scopus since 2002 - Évolution du nombre de citations dans Scopus depuis 2002 . 
Finally, for a journal initiated by scientific institutions, internal communication is just as important as communication at the national and international level. This article is part of this communication process The support of the academic and financial authorities is also essential.

\section{Bibliography}

Baudoin J.-P., 1997. Éditorial. Biotechnol. Agron. Soc. Environ., 1(1), 3.

Bon M., 2015. Principles of the self-journal of science: bringing ethics and freedom to scientific publishing. Self J. Sci., 46.

Butler D., 2013. The dark side of publishing. Nature, 495, 433-435.

Callaway E., 2016. Publishing elite turns against impact factor. Senior staff at societies and leading journals want to end inappropriate use of the measure. Nature, $\mathbf{5 3 5}$, 210-211.

Casadevall A. \& Fang F.C., 2014. Causes for the persistence of impact factor mania. MBio, 5(2), 1-6.

Crawford W., 2017. Gold Open Access journals 2011-2016. Livermore, CA, USA: Cites Insights Books.
Galligan F. \& Dyas-Correia S., 2013. Altmetrics: rethinking the way we measure. Ser. Rev., 39(1), 56-61.

Margalida A. \& Colomer M.À., 2016. Improving the peerreview process and editorial quality: key errors escaping the review and editorial process in top scientific journals. PeerJ, $4 \mathrm{e} 1670$.

Murphy F., 2016. An update on peer review and research data. Learn. Publ., 29(1), 51-53.

Pochet B., 2002.Éditorial. Biotechnol. Agron. Soc. Environ., 6(1), 3.

Pochet B. \& Baudoin J.-P., 2009. Éditorial. Biotechnol. Agron. Soc. Environ., 13(1), 75-76

Satyanarayana K., 2010. Impact factor and other indices to assess science, scientists and scientific journals. Indian J. Physiol. Pharmacol., 54(3), 197-212.

Wenzler J., 2017. Scholarly communication and the dilemma of collective action: why academic journals cost too much. Coll. Res. Libr., February, 183-200. 